\title{
Storage of surface flows through groundwater recharge
}

\author{
M C CHATURVEDI* and V K SRIVASTAVA \\ *Applied Mechanics Department, Indian Institute of Technology, Hauz Khas, New Delhi \\ 110016 , India. \\ †Raipur Engineering college, Raipur, India.
}

\begin{abstract}
The Ganga basin in India has a serious problem of water availability. The basin, which is only one twelfth of the United States in area, has a population greater than the total us population, and is increasing at a rate of $2.5 \%$ per annum. About $77 \%$ of the population is engaged in agriculture which is totally dependent on irrigation, as almost $85 \%$ of the rainfall comes down in 2-3 monsoon months. Surface storage possibility is extremely limited, but groundwater recharge appears feasible, since sedimentary alluvial formations extend to depths of thousands of metres. Three alternative schemes of groundwater recharge have been proposed. One involves pumping heavily along perennial rivers prior to the monsoon so as to lower the water-table and promote induced groundwater recharge. The second proposes a similar approach along nonperennial rivers. The third involves irrigation during the monsoon with groundwater lowered adequately in the non-monsoon period so that enough induced groundwater recharge takes place to provide adequate supplies for non-monsoon months. A simulation-optimization model has been developed to study the surface flow-groundwater interaction and has been applied to study comparative cost effectiveness of the three alternate approaches. Sensitivity analysis has also been carried out. It is shown that the third scheme is the most attractive.
\end{abstract}

Keywords. Surface flows; induced ground water recharge; groundwater simulation; sensitivity analysis; simulation-optimization model.

\section{Introduction}

The Ganga basin has a serious problem of water availability. Surface storage possibilities are extremely limited but groundwater recharge appears feasible as sedimentary alluvial formations extend to thousands of meters depth.

Of the several ways of ground water recharge, three schemes of ground water recharge appear to be particularly promising. The first involves pumping heavily along perennial rivers prior to the monsoons so as to lower the groundwater level to promote induced groundwater recharge. The second proposes a similar approach along non-perennial rivers. The third involves irrigation during monsoons with groundwater lowered adequately in the non-monsoon period so that enough induced groundwater recharge takes place to provide adequate supplies for non-monsoon month requirements.

A simulation-optimization model has been developed to study the surface flowgroundwater interaction and has been applied to study the feasibility and comparative cost-effectiveness of the three alternatives. Sensitivity analysis has also been carried out and the third scheme appears to be the most attractive.

This paper has been reprinted with permission from the American Geophysical Union: Chaturvedi $\mathbf{M}$ C and Srivastava V K Water Resources Res. 15: 1156-1166 (1979), (C) AGU 


\section{The issue}

The water availability in the Ganga basin in India is acute from several considerations. It covers an area about one-twelfth of, and has a population almost that of the U.S.A. or roughly one-tenth of the world's population. The population growth rate of about $2.0 \%$ is one of the highest in the world and the GNP per capita of about $\$ 100$ is one of the lowest. About $77 \%$ of the population is engaged in agriculture. The average foodgrain yields of $1000 \mathrm{~kg} /$ hectare are low, comparing unfavourably even with yields of $2500 \mathrm{~kg} /$ hectare in neighbouring regions of Punjab in India itself or $1800 \mathrm{~kg} /$ hectare in China, or $5000 \mathrm{~kg} /$ hectare in Japan (Chaturvedi 1976).

Irrigation is crucial for scientific agriculture as over the years there is a long arid period, punctuated by a short monsoon period of heavy rains and floods, when nearly $84 \%$ of the rainfall takes place. Storage of monsoon waters is essential but surface storage possibilities are very limited. The plains have, however, alluvial deposits thousands of meters deep. Thus storage of the monsoon waters through induced groundwater recharge is quite feasible. The physiographic and hydrologic features of the basin are shown in figure 1 and figure 2 respectively.

\subsection{Possible alternatives for surface water storage}

Revelle \& Herman (1973) suggested storing of monsoon flows of the perennial rivers through induced groundwater recharge by lowering of the groundwater table in the adjoining areas by heavy pumping for irrigation prior to monsoons. A schematic layout of tube wells is shown in figure 3. This has been designated scheme I for induced groundwater recharge along perennial rivers (PR). It may be noted that there is no pumping during the monsoon period. Independently, Rama (1971) had also suggested a similar scheme along non-perennial rivers. This has been designated as scheme II for induced groundwater recharge along non-perennial rivers (NR). A third possibility, suggested by Chaturvedi (Srivastava 1976), is through conjunctive surface irrigation during monsoons and pumped groundwater irrigation during arid winter and summer months. The monsoon irrigation is proposed through unlined canals with the capacity to carry the demanded monsoon irrigation (called kharif) plus surplus water designed to recharge the groundwater. The groundwater pumping in the previous arid months is designed so that the natural rainfall recharge and induced monsoon flow recharge equals the irrigation demand during this period (called rabi). The groundwater level is also a decision variable to be suitably designed to obtain satisfactory induced groundwater quantity and optimal pumped quantity. The monsoon irrigation channels shall be unlined while the non-monsoon channels shall be lined as shown in figure 4. This has been designated scheme III and is called kharif channel conjunctive use $(\mathrm{Kc})$. This study relates to the development of a mathematical simulationoptimization model and a comparative cost effectiveness study of the three schemes.

\section{The model}

Analytically, the problem is of modelling the stream-aquifer response given the stream dimensions, flow specification and pumpage capacities. Next, for several pumpage configurations, the optimal pumping policy has to be determined. On this basis, preliminary selection can be carried out between the three alternative schemes. Having 


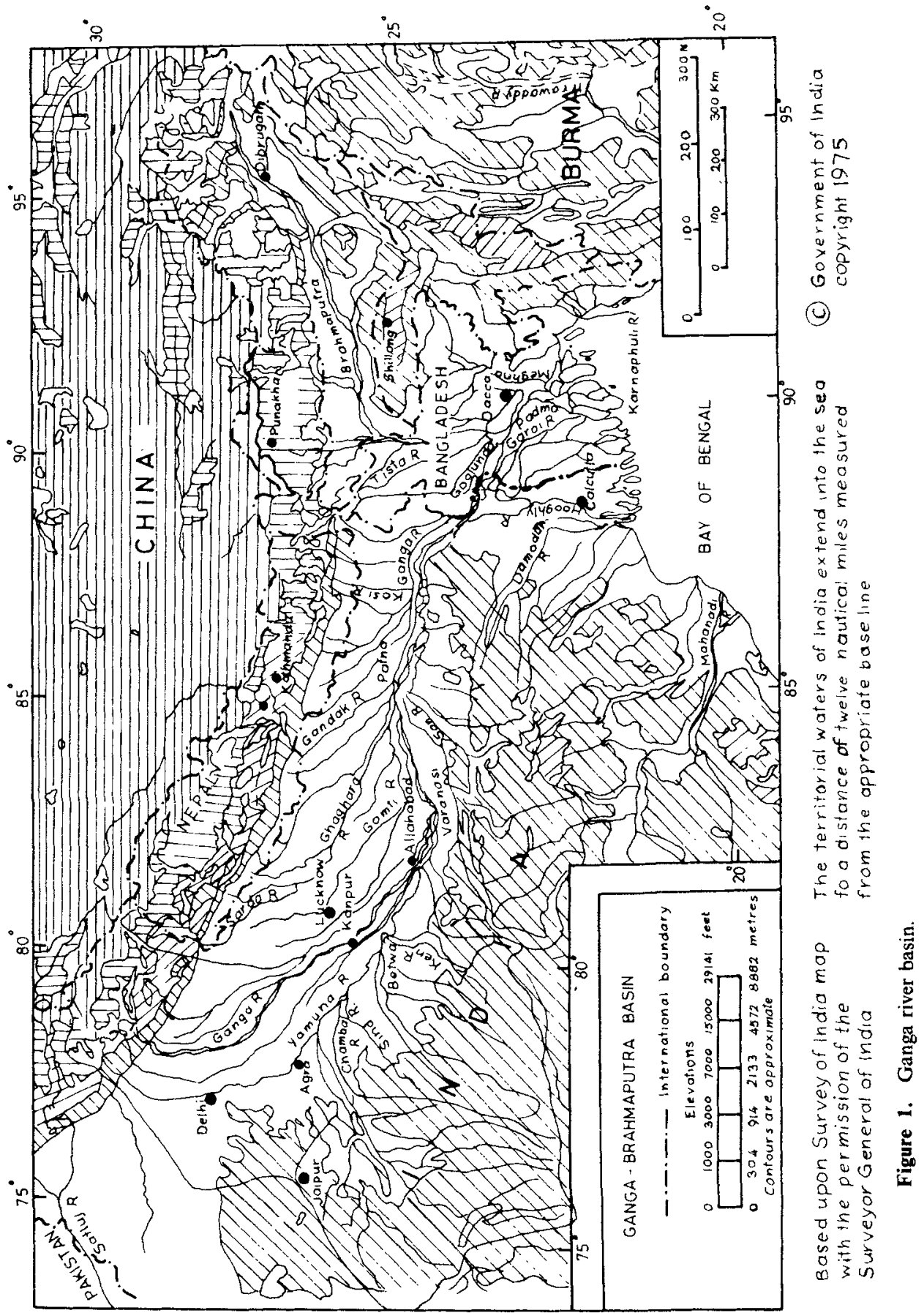




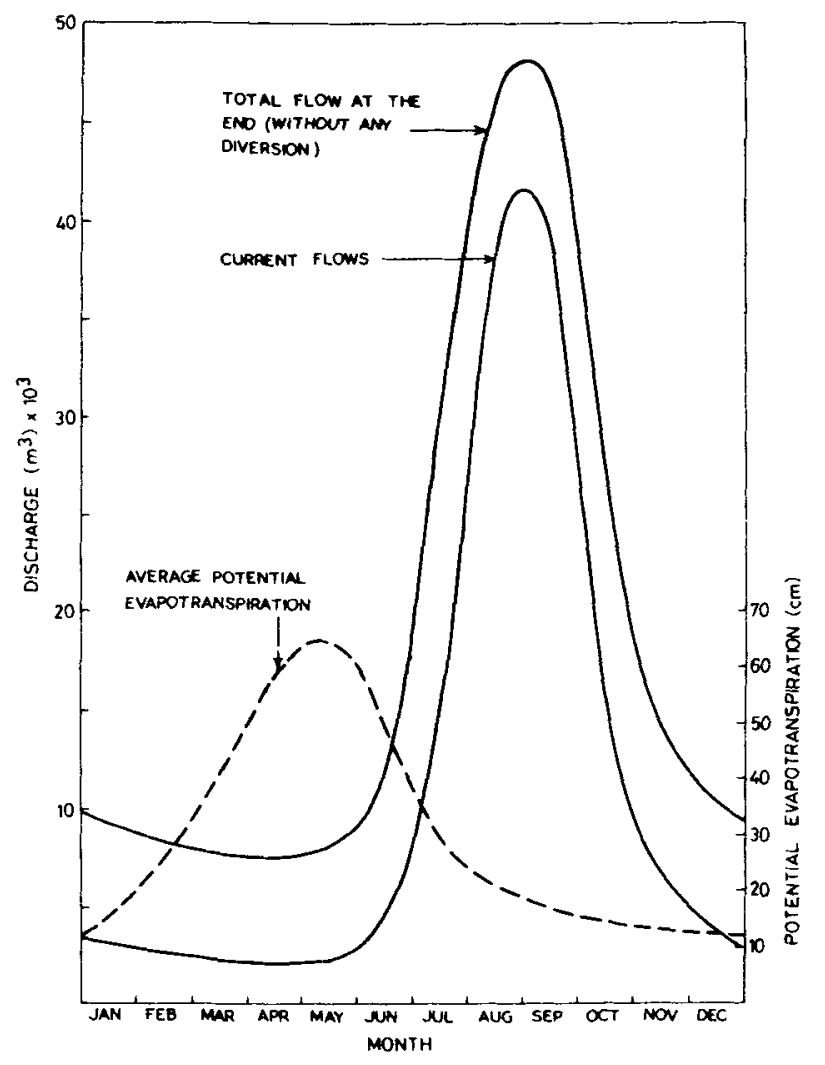

Figure 2. Hydrologic characteristics.

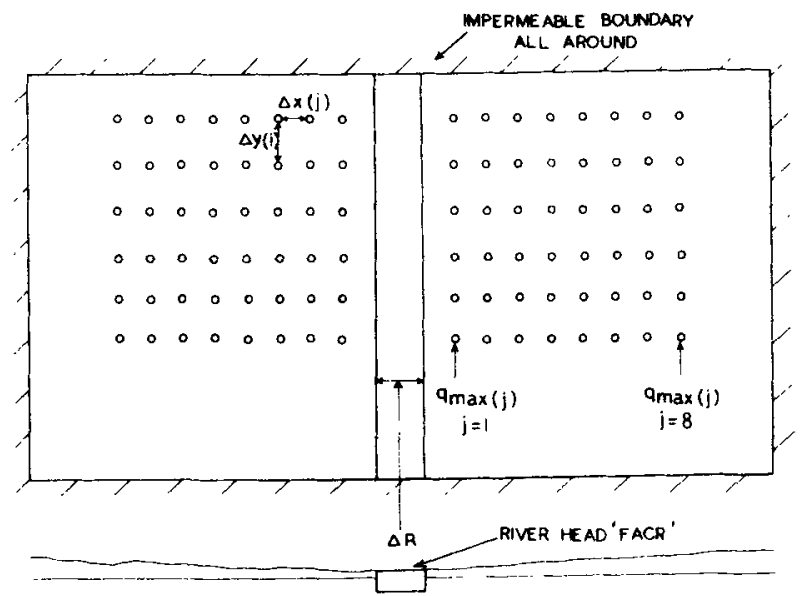

Figure 3. Schematic layout of wells: $q_{1} \ldots q_{8}$-variable pumping rate can be fixed a priori and changed during a pumping season, and from season to season, depending on demand; $\Delta x(j), \Delta y(i), \Delta R(j)$-grid spacing in $x$ direction, $y$ direction, and width of river respectively, variable from node to node but fixed during a particular simulation study; FACR-variable but fixed during a pumping period simulated. 


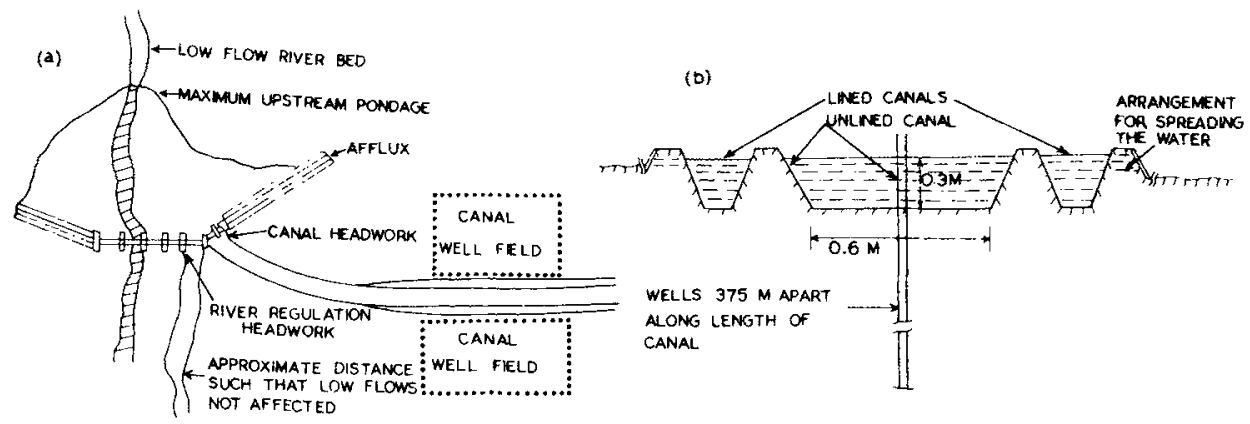

Figure 4. Canal offtake and schematic plan of induced groundwater recharge through kharif canal. a) Plan, b) Section of a typical field distributary.

chosen the preferred candidate system, a second study for optimal system configuration can be designed by having other studies give production functions for various capacity tubewells, or lateral wells, etc. The present study has been confined to the first part only.

Stream aquifer interaction models using the finite difference approach have been developed lately by many researchers (Pinder \& Bredehoeft 1968, Maddock 1969; Pinder 1970; Prickett \& Lonnquist 1971; Trescott 1973; Bredehoeft \& Young 1970; Young \& Bredehoeft 1972, etc.). The two techniques which have found favour in the solution of the partial difference equation are the Peacemen \& Rachford (1955) and the Duglas \& Rachford (1956) alternating direction implicit (ADI) techniques. A number of modifications of the basic ADI method have been devised (Birkhoff et al 1962; Wachspress 1965) but have not been used in groundwater modelling. The ADI technique wes used in this study.

Mathematical programming models have been coupled to simulation models to determine the optimum policy (Young \& Bredehoeft 1972; Maddock 1974). Drawing on earlier work and incorporating suitable features, a simulation-linear programming model was developed by Srivastava (1976) to model the three proposed schemes. The simulation model is essentially as developed by earlier researchers though some improvements in the coupling to a linear programming model, have been made.

The basic equation of motion of water through a porus medium oriented colinear with the principal components of hydraulic conductivity $K_{x x}$ and $K_{y x}$ is,

$$
\frac{\partial}{\partial x}\left(T \frac{\partial h}{\partial x}\right)+\frac{\partial}{\partial y}\left(T \frac{\partial h}{\partial y}\right)=S \frac{\partial h}{\partial t}+Q_{(x, y, t)}-q_{(x, y, t)}^{1}+q_{(x, y, t)}^{2}
$$

where $T=$ non-homogeneous transmissivity $\left(L^{2} / T\right), h=$ hydraulic head $(L)$, $S=$ coefficient of storage or storativity, $Q_{(x, y, t)}=$ rate of pumping per unit area $(L / T)$ $q_{(x, y, t)}^{1}=$ rate of leakage from confining layer having storage capability such as leakage from lake or stream bed $(L / T), q_{(x, y, t)}^{2}=$ rate of evapotranspiration as discharge from water-table aquifer $(L / T)$. The leakage given by Pinder \& Bredehoeft (1968) and evapotranspiration given by Trescott (1973) are approximated as follows:

$$
q^{1}=\frac{k_{z}}{M}\left(H_{0}-H\right)
$$

where $k_{z}=$ vertical permeability of the bed $(L / T), M=$ thickness of bed through which leakage takes place $(L), H_{0}=$ water-level in the river $(L), H=$ starting level of 
groundwater table held fixed $(L)$, and

$$
q^{2}=\frac{k_{E}}{H_{y}}\left(H_{y}-H_{L}\right)
$$

where $k_{E}=$ maximum evapotranspiration rate $(L / T), H_{y}=$ depth below top of the land surface at which evapotranspiration ceases $(L), H_{L}=$ depth of water table below the top of the land surface $(L)$. The finite difference equations and solution methodology is given in appendix A. The grid is shown in figure 5.

A simple linear programming model has been formulated with an objective function which optimises the pumping schedule and computes the overall cost of pumping which consists of simulation of the cost of pumping at each individual well. The goal of the basin management authority is the minimisation of the average annual cost of pumping to meet the demand for water. Alternative development solutions to the problems are therefore ranked according to the criteria

$$
\min Q=\frac{1}{T} \sum_{i=0}^{t=T} \sum_{j=1}^{N}\left(h_{(j)} \cdot q w_{(j)}\right) \Delta t
$$

in which $t$ is the total pumping period broken up into several parts of $\Delta t$ over which the objective function is evaluated, $N$, the number of pumps which exist in a row, $q w_{(j)}$, the pumping rate of pump at $j$ th column node across the direction of flow of the river with the pump nearest to the river being $q w_{(j)}, h_{j}$, the total pumping head or lift at column node $j$ determined from the aquifer model, and $Q$, the measure of the average annual net operating cost of pumps.

The objective function is minimized subject to the following constraints:

$$
q w_{(j)} \geqslant 0(j=1,2, \ldots, N),
$$

in which $q w_{(j)}$ is the pumping rate of the well at column node $j$ in each row, and $N$ is the total number of installed pumps in a row and is the number of independent variables to each of which $q_{(j)}$ as the pumping capacity is assigned. In the cases studied $N$ takes a maximum value of up to 8 pumps in a row.

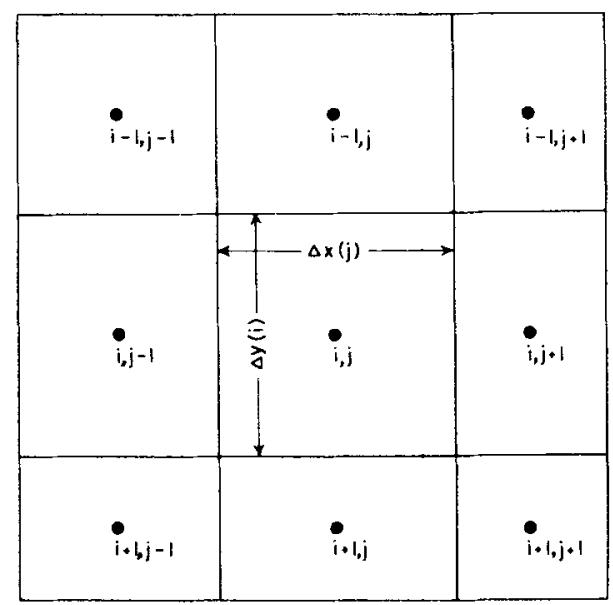

Figure 5. Nodal array for digital model. 
Equation 5 has the non-negativity restrictions or constraints

or

$$
q w_{(j)} \leqslant q_{\max (j)}
$$

$$
q_{\max (j)}-q_{(j)}=0,
$$

in which $q_{\max (j)}$ is the maximum installed capacity of the pump at column node $j$, which means that the pumping capacity assigned by the linear program solution cannot exceed the installed pumping capacity at that node. Also

$$
\sum_{j=1}^{j=N} q w_{(j)}=q_{\text {total }},
$$

in which $q_{\text {total }}$ is the maximum pumping rate permitted of producing water, with the combined capacity of all pumps not to produce more than this water for each row of wells being the same for all rows.

Constraints of the type

or

$$
q w_{(j)} \geqslant q_{\min (j)},
$$

$$
q_{\min (j)}-q_{j}=0
$$

in which $q_{\min (j)}$ is the minimum pumping capacity which must be assigned to each group at column node $j$, have not been considered. The reason for not including such constraints is that a pump which is uneconomical to operate can be shut down or assumed to be non-existent to find the optimal well field geometry. Such constraints can, however, be included by a simple modification of the program to include such a condition when the situation requires it.

It may be noted that the objective ranking function is not an economic function in the usual sense as the monetary value term and discounting function have not been incorporated in it. It is, however, quite adequate for ranking purposes. The generalised flow chart is given in figure 6. The computer listing is given by Srivastava (1976).

\section{Analysis}

As a preliminary estimate Revelle \& Herman (1973) had proposed installing a battery of tubewells of capacity 0.0285 cumecs each at $0.4 \mathrm{~km}$ distance, at right angles and parallel to the river. Eight wells on either side were proposed to give the requisite discharge. Considering the river as $0.8 \mathrm{~km}$ wide and the nearest point where the wells can be placed as also $0.8 \mathrm{~km}$ away from the river bank, we get the total width of $0.8 \mathrm{~km}$ on either side with a discharge of 2.25 cumecs per $\mathrm{km}$ length of river. The schematic representation of the well field is given in figure 7.

For non-perennial rivers the same scheme (river dimensions) and geo-hydrologic parameter were adopted. Only the water availability time was assumed as 120 or 240 days for two hydrologic conditions. This is not entirely representative as the dimensions will be smaller and flow will not be constant for the entire period. Alternatively, these time periods could be obtained through small storage works. For the perennial river also discharge was assumed constant over the year although flow would vary with time. These alternative details could be modelled but at this stage the objective was only to develop an analytical tool and to get an idea of the comparative and general order of magnitude under the three possible schemes, and their sensitivity 


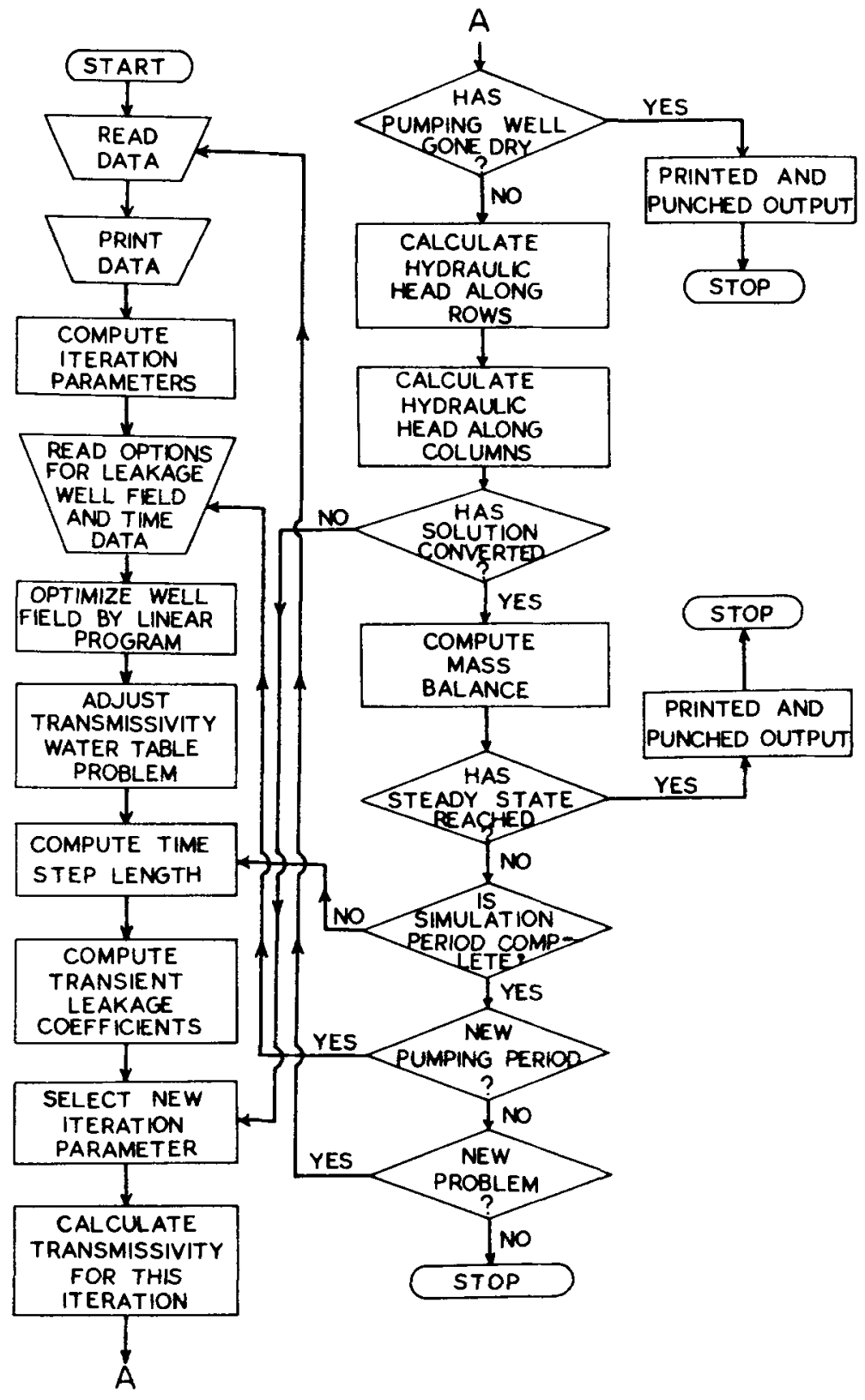

Figure 6. Generalized flow chart for combined hydrologic and economic digital simulation model.

to hydrogeological parameters. Many design improvements can be made. Instead of vertical tubewells radial wells could be used. Duration of water availability in nonperennial streams during monsoon periods could be increased by having some storage structure as stated above. Naturally, these issues were not considered at this stage.

In scheme I (PR), during summer season pumping, some of the low flows can be withdrawn due to heavy pumping along the rivers at this time. These have to be 


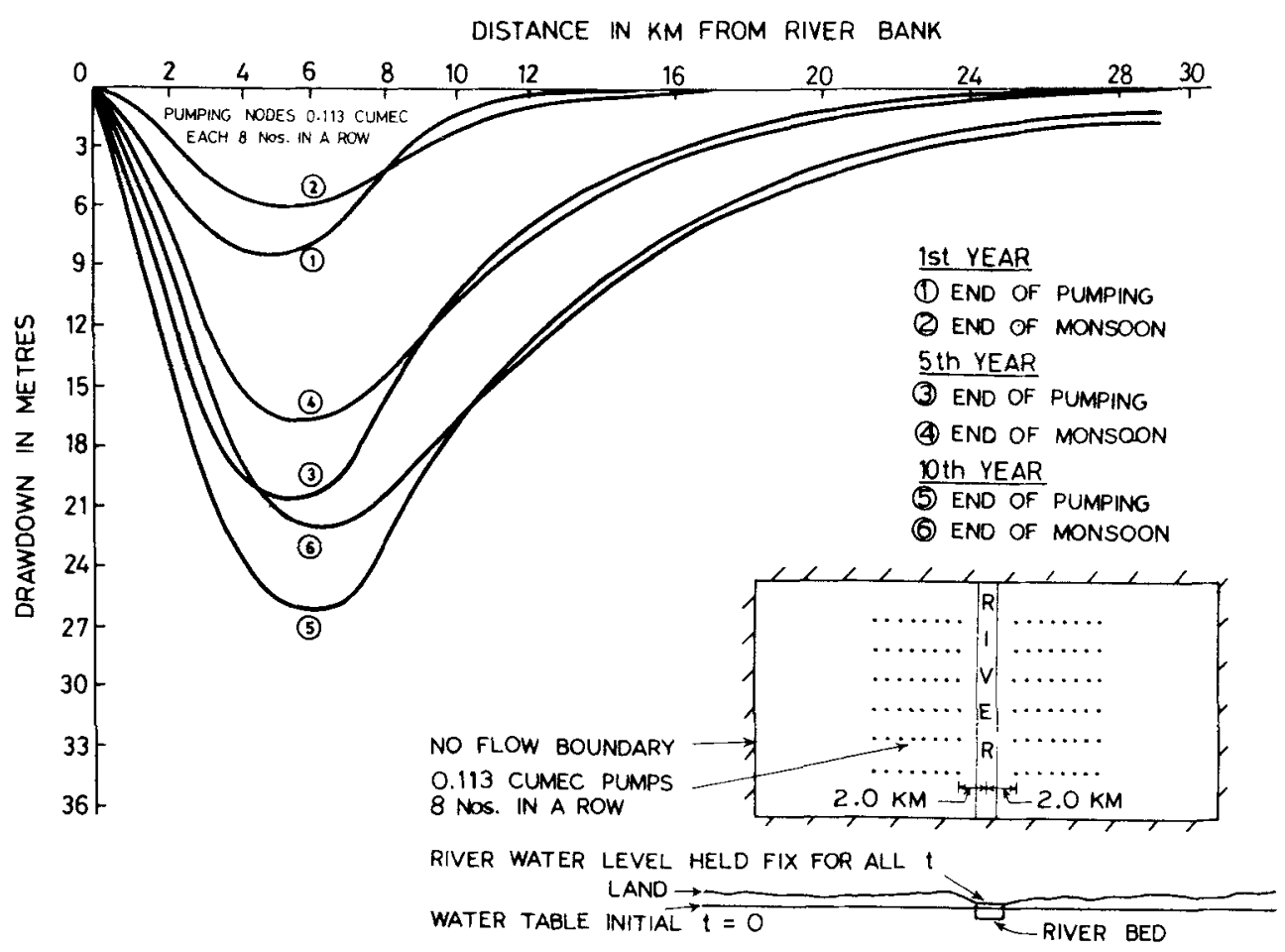

Figure 7. Drawdown with no rainfall recharge for perennial river.

returned and the net utilizable groundwater recharge will be the total withdrawals minus these low flow withdrawals. The low season withdrawals given by the model are on the higher side as real life low flows are almost one-fiftieth of monsoon flows, and the scheme is unfavourably penalised. Further, these low season withdrawals can be completely avoided by having a pumping scheme at a distance from the river on a diversion canal. These issues were not considered at this stage.

The river, aquifer and pumping characteristics for scheme I and II are given in table 1. In scheme III, a typical kharif channel proposed for irrigation will carry a discharge of 0.09 cumecs for kharif requirements of irrigation. If a channel is designed to carry a discharge of an additional 0.056 cumecs during the kharif season of 120 days which will leak into the aquifer which was pumped during the dry season of 240 days, the kharif channel will work as a recharging channel during the kharif season. (Additional discharge for a pumping and recharge season of 180 days will be 0.028 cumecs only).

The objective is to get water at minimum cost. The costs include the cost of conveyance of water to areas needing irrigation. An associated objective is to capture as much monsoon water as possible per unit length (net low flow returns in each perennial case). The issue has multi-objectives but in the first instance we have compared the alternatives from the point of view of cost, developing a design that shall enable us to recharge targeted amounts of water. Conveyance costs were neglected as this did not affect the comparative ranking. The multi-objective analysis has to be in terms of appropriate well field intensity and may be taken up later when more detailed design 
Table 1. River, aquifer, pumping characteristics of schemes I and 11 .

\begin{tabular}{|c|c|c|}
\hline \multirow[t]{7}{*}{ A. } & \multicolumn{2}{|l|}{ River } \\
\hline & Width & $800 \mathrm{~m}$ \\
\hline & Bed thickness & $15 \cdot 3 \mathrm{~m}$ \\
\hline & Hydraulic conductivity & $2.5 \mathrm{~m}$ per day \\
\hline & Depth of flow & $3 \mathrm{~m}$ \\
\hline & Duration of flow & 120 days for non-perennial river \\
\hline & Specific storage of river bed. & 00000656 per $\mathrm{m}$ \\
\hline \multirow[t]{5}{*}{ B. } & Aquifer & \\
\hline & Hydraulic conductivity & $15.3 \mathrm{~m}$ per day \\
\hline & Specific yield & 0.25 \\
\hline & Thickness & $305 \mathrm{~m}$ \\
\hline & Initial water table & $305 \mathrm{~m}$ above impervious datum \\
\hline \multirow[t]{4}{*}{ C. } & Pumping & \\
\hline & Rate of withdrawal & 1.25 cumecs $/ \mathrm{km}$ length of river on either side \\
\hline & Duration & $\begin{array}{l}240 \text { days for non-perennial river; } 240 \text { and } 180 \\
\text { days for perennial river for reasons discussed } \\
\text { later }\end{array}$ \\
\hline & Distance between pumps & Grid size $6 \times 39$ square grid \\
\hline
\end{tabular}

Table 2. Comparative operating performance of the three schemes.

\begin{tabular}{lcc}
\hline & $\begin{array}{c}\text { Average annual objective } \\
\text { function at steady state } \\
\mathrm{mm}^{3} / \mathrm{s}\end{array}$ & $\begin{array}{c}\text { Usable water } \\
\text { for same } \\
\text { quantity pumping } \\
\text { ha m } \times 10^{3}\end{array}$ \\
\hline Perennial river & 64.00 & 1.680 \\
Non-perennial river & 66.40 & 4.675 \\
Recharging kharif channel & 21.03 & 4.675 \\
\hline
\end{tabular}

Note: (1) Pumping duration 240 days, recharge duration 120 days (2) Total pumping 2.250 cumecs (3) Aquifer parameters same for all three schemes (4) Rainfall recharge not taken into account in any scheme.

analysis is carried out as part of a systems study. For the preliminary comparative analysis the objective function of (4) was used as surrogate for cost. The results of the comparative analysis are shown in table 2 . The results show that scheme III, the kharif channel conjunctive scheme, is much more efficient than scheme I or II, i.e. the induced groundwater schemes along perennial or non-perennial rivers. On detailed analysis, scheme III will turn out to be even better, as favourable assumptions about availability of water in schemes I and II have been made and conveyance costs will be minimal in scheme III.

Both schemes I and II have almost the same cost for gross induced groundwater recharge but scheme $I$ is comparatively inefficient in terms of conserving the resources and correspondingly uneconomical as the low flow seasons are diverted and have to be returned in scheme $I$. These figures are only indicative as scheme $I$ is penalised and scheme II is favourably supported. The low flow diversions will be much less as flow breadth and depth will be much less during this period than what is assumed. On the other hand, much more pumping will be required in scheme II as flow dimensions and 
availability period corresponding to scheme I during monsoons shall not be available unless storage structures are constructed which will naturally increase the unit cost. Creative solutions for scheme I are also possible for increasing the efficiency by pumping along diversions. Therefore, for taking decisions more detailed hydrologic, hydraulic and engineering-economic analyses are needed. Furthermore, these schemes are not mutually exclusive.

The important issue of long-term salt-balance has not been analysed in this case and must be studied in any further study. Reference may therefore be made to the classic study of the Indus basin by the Harvard group (Thomas \& Burden 1965).

\section{Sensitivity analysis}

Analysis has been carried out for a range of configurations and parameters in each of these three cases to get an idea of the dynamics of the system. Some of the results for scheme I are given in table 3. First, keeping the capacity constant, what is the effect of the location of the wells? It is seen that the optimal case has two tubewells near the river. Based on this result, radial wells appear to be attractive. Secondly, for the perennial case net usable groundwater recharge increases, but at increased unit cost for a spread out field. The implication is that if pumps are proposed to be spread out along the length of the river to reduce groundwater lowering, there is a corresponding penalty in the increased lateral dimension to maintain unit availability per unit length of river. Thirdly, increased pumping time increases unit costs as drawdown increases while groundwater recharge decreases, as proportionately larger amounts of water have to be returned during the low flow season. Similar studies have also been carried out for the other two schemes.

The sensitivity of the objective function to change in the aquifer parameters was also carried out for each of these three cases. For one case, viz the non-perennial case, the results are shown in table 4.

The changes for other cases are of the same order of magnitude. It will be seen that the objective function is most sensitive to changes in aquifer hydraulic conductivity, next to the specific yield, and comparatively insensitive to river bed hydraulic conductivity.

The drawdown, yearly recharge and pumped withdrawal per kilometre length of river for some of the configuration and aquifer parameters are shown in figure 13.

Figure 7 shows that drawdown varies spatially and temporarily for a given configuration. No rainfall recharge was assumed. The specific yield value adopted was 0.25 . If a different value of specific yield or additional rainfall recharge is adopted general characteristics remain the same and only the drawdowns vary.

For a specific yield of $0 \cdot 1$ the drawdown at the end of the tenth year changed from 26 to 35 metres while with normal rainfall recharge of $15 \mathrm{~cm}$ annually, the drawdown at the tenth year was changed only marginally to 23 from 26 metres. The yearly recharge and pumped withdrawal per kilometer length of river is shown in figure 8 . It will be seen that a steady state is not reached even after 10 years. The drawdown will go down further and objective function worsen, apparently asymptotically. Even if normal rainfall recharge is taken into account, although the yearly recharge is increased, a steady state is not reached after 10 years. However, if the value of the specific yield was 0.25 , steady state would be reached with normal rainfall recharge in about 10 years.

The effect of well configuration has also been studied by replacing eight wells by only 


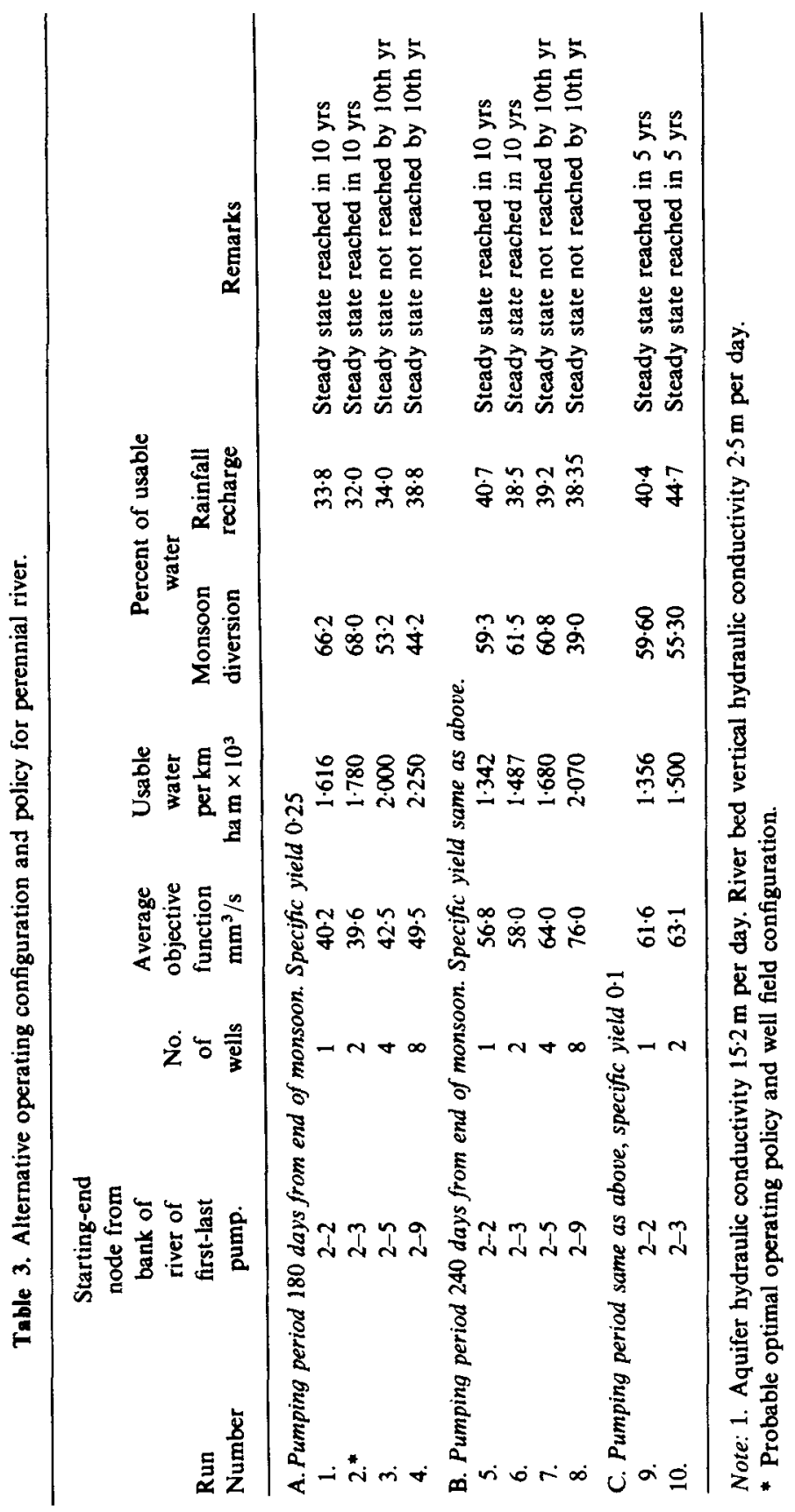


Table 4. Sensitivity of objective function to changes in aquifer parameters for non-perennial rivers

\begin{tabular}{|c|c|c|c|c|}
\hline $\begin{array}{l}\text { Specific } \\
\text { yield }\end{array}$ & $\begin{array}{c}\text { Aquifer } \\
\text { hydraulic } \\
\text { conductivity } \\
\text { (m/day) }\end{array}$ & $\begin{array}{c}\text { River bed } \\
\text { hydraulic } \\
\text { conductivity } \\
\text { (m/day) }\end{array}$ & $\begin{array}{l}\text { Average } \\
\text { objective } \\
\text { function } \\
\left(\mathrm{m} \mathrm{m}^{3} / \mathrm{s}\right)\end{array}$ & Remarks \\
\hline $0-1$ & $15 \cdot 2$ & $2 \cdot 5$ & $120 \cdot 0$ & Well field geometry, \\
\hline $0 \cdot 25$ & $15 \cdot 2$ & $2 \cdot 5$ & $82 \cdot 3$ & operating policy, and \\
\hline $0 \cdot 1$ & $22 \cdot 8$ & $2 \cdot 5$ & 93.8 & other specifications \\
\hline $0 \cdot 1$ & $22 \cdot 8$ & $3 \cdot 75$ & $93-6$ & remain constant. \\
\hline
\end{tabular}



Figure 8. Yearly recharge and pumped withdrawal per kilometer length of perennial river.

one well of equivalent capacity. The drawdown with rainfall recharge in this case is shown in figure 9. The corresponding values of objective function and induced groundwater recharge have been given in table 3 . Obviously, in actual designs appropriate configurations dependent on geophysical characteristics and natural as well as engineered hydrological conditions would have to be developed.

Corresponding to the conditions of the perennial case presented in figures 7 and 8 , the response for the non-perennial case is shown in figures 10 and 11 , respectively. Although the annual recharge was much higher than in scheme I, the steady state was far from being obtained even after 10 years. The implication is that the objective function is going to be worse than that shown in table 2 .

The corresponding figures for scheme III, the kharif channel, are shown in figures 12 and 13 respectively. It is to be noted that the pumps installed are of very low pumping 


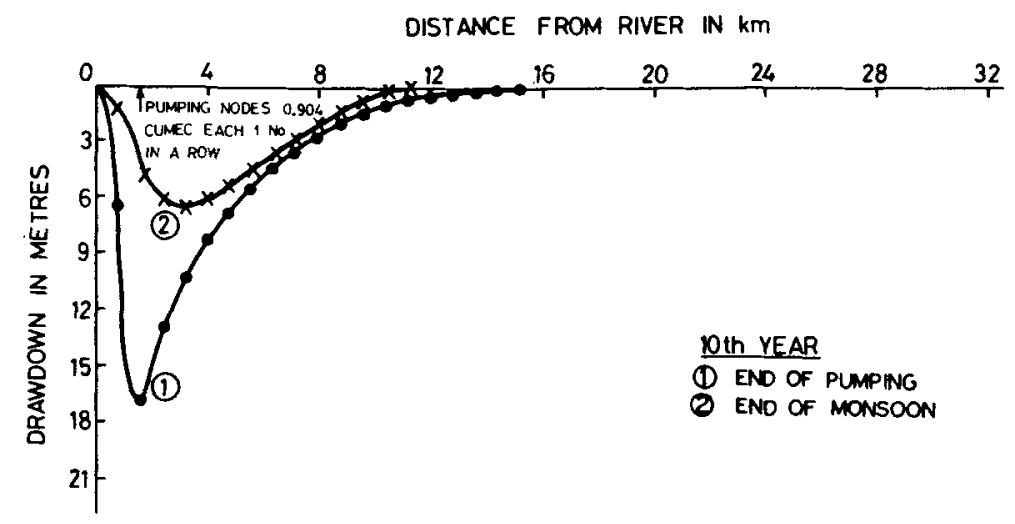

Figure 9. Drawdown with rainfall recharge for perennial river.

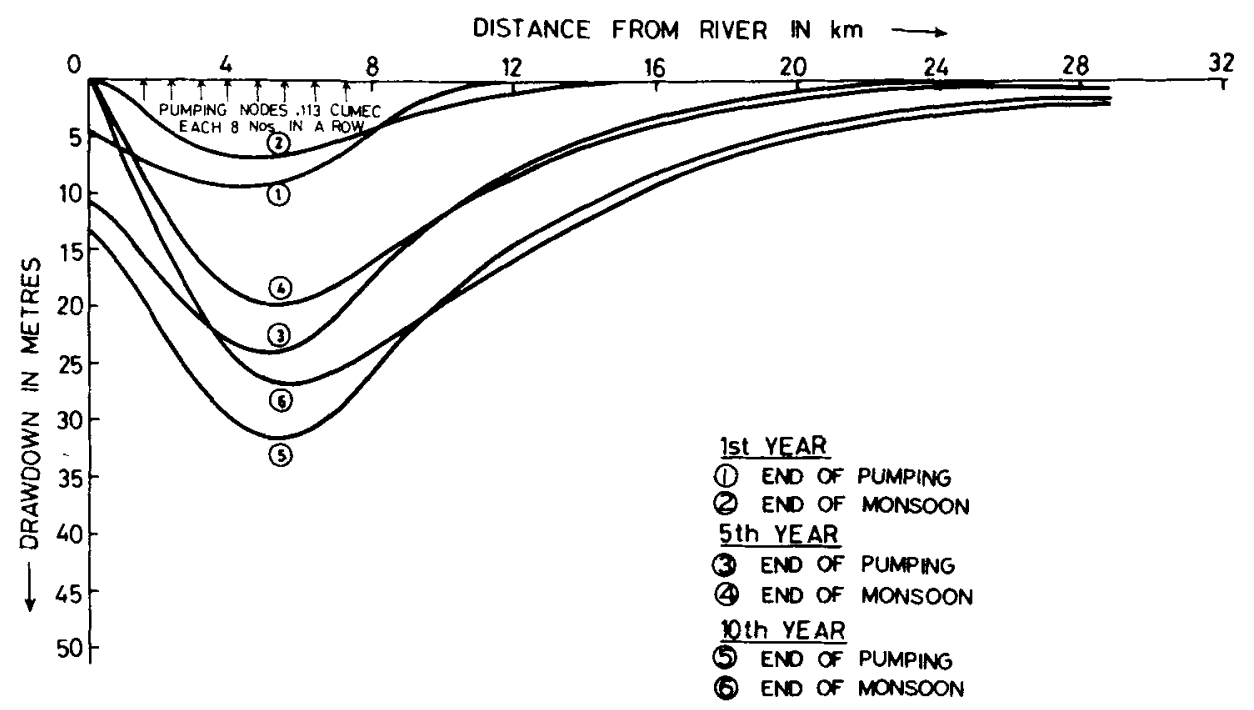

Figure 10. Non-perennial river drawdown with no rainfall recharge.

capacity and uniformly spread over the whole area and therefore the water table goes down uniformly all over the aquifer due to the pumping stress. The drawdown, therefore, is a horizontal line in all cases at the end of both pumping and the recharge cycle. Steady state is reached, in contrast to the earlier two schemes, within five years.

\section{Conclusion}

The study is exploratory. An aquifer-stream flow interaction simulation-linear programming model has been developed. Order of magnitude behaviour for three schemes designed to conserve the monsoon flows in the Ganges basin by induced groundwater recharge and the sensitivity to engineering decisions, hydrogeological parameters and hydrological conditions has been quantified. Technical feasibility of storage of large monsoon flows has been demonstrated. 


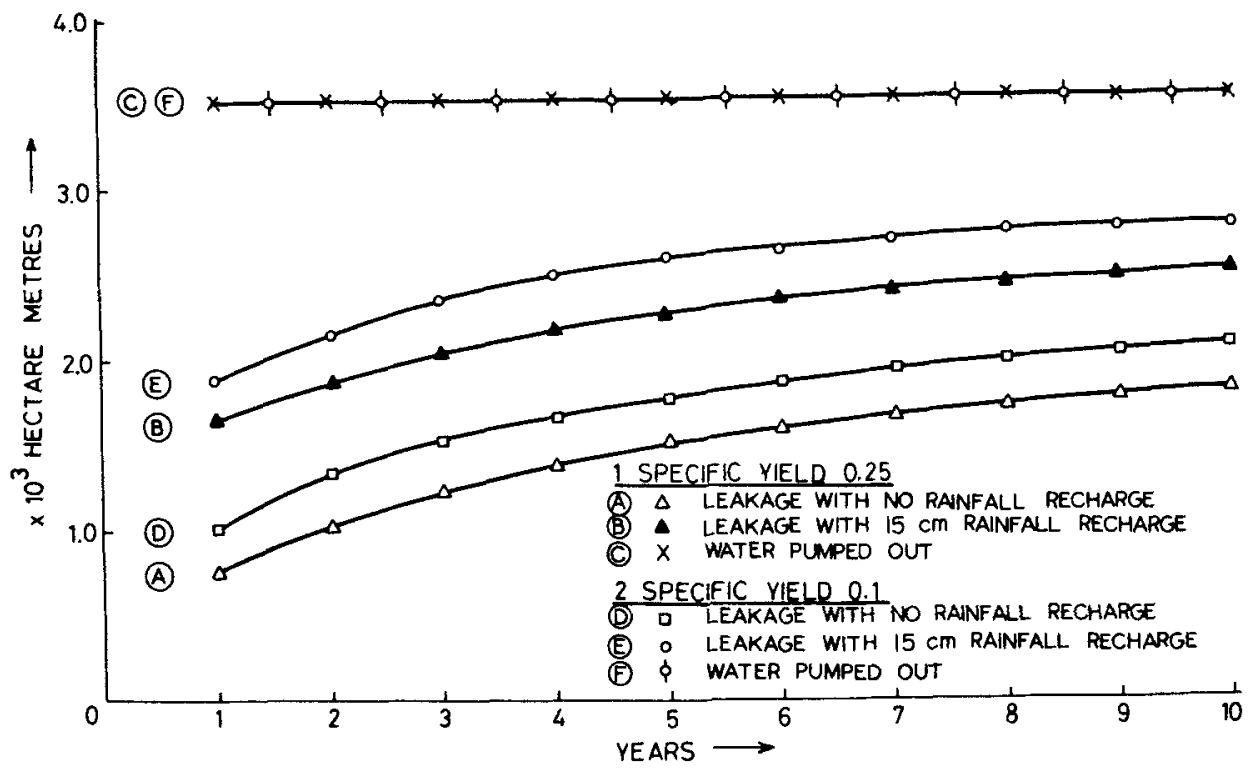

Figure 11. Yearly recharge and pumped withdrawal per kilometre length of non-perennial river.

DISTANCE FROM CHANNEL IN MT

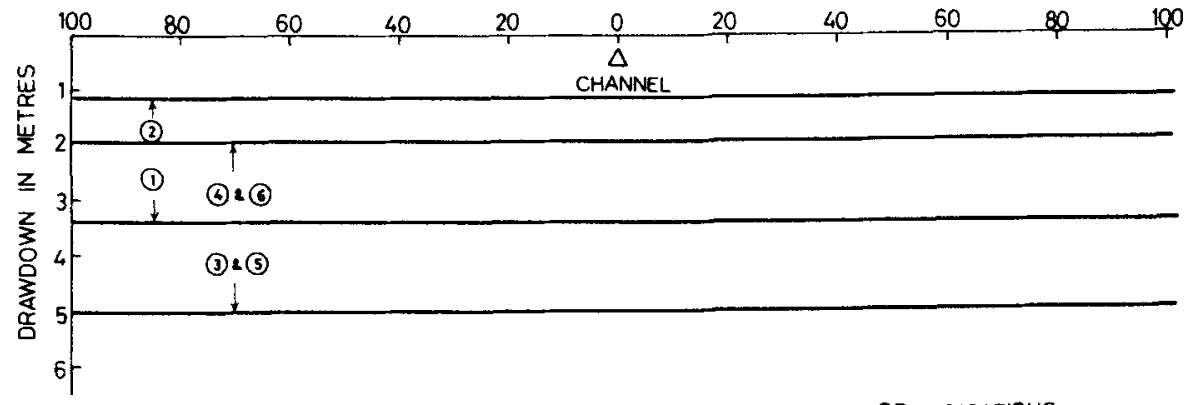

Ist YEAR

(1) END OF RABI SEASON

(3) END OF KHARIF SEASON

5 th YEAR

(3) END OF RABI SEASON

(4) END OF KHARIF SEASON

10th YEAR

(5) END OF RAB! SEASON

(c) END OF KHARIF SEASON

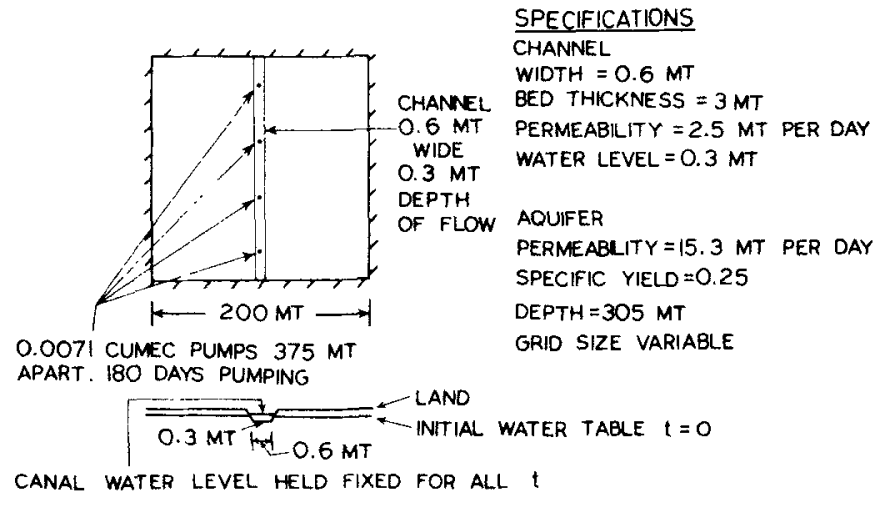

Figure 12. Drawdown with recharge during kharif season and pumping during rabi season. 
NON PERENMIAL CHANNEL

RECHARGE DURING SIX MONTHS KHARIF SEASON WITHDRAWAL DURING SIX MONTHS RABI SEASON PER DO MT LENGTH OF CHANNEL

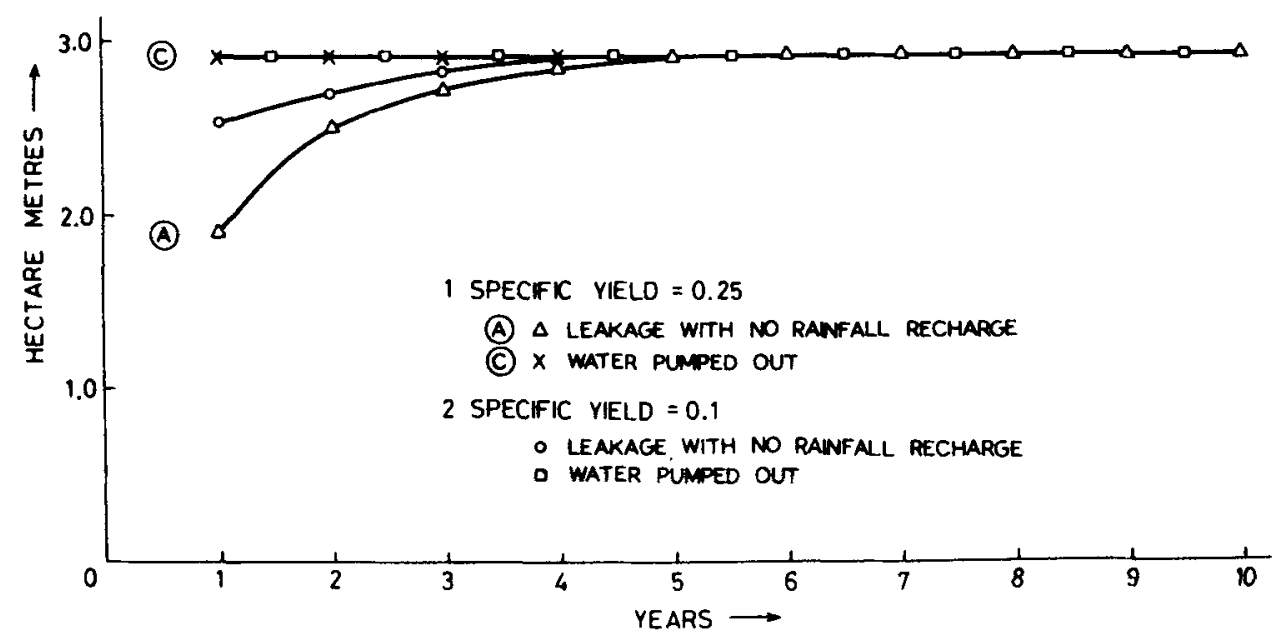

Figure 13. Yearly recharge and pumped withdrawal per kilometre length of non-perennial river.

Economic feasibility is a matter of detailed systems planning and design. Of the three schemes, the third, viz kharif channel conjunctive ground water development appears to be very attractive. The schemes are not mutually exclusive and their choice depends upon general hydrologic-physiographic situations. For instance, in the three continuous areas of the Indo-Gangetic basin, each has some advantage over the other. In Punjab, at the western end where all the perennial river flows have been stored, scheme II is being explored. In Uttar Pradesh and Bihar, viz., the western and central Ganges basin, where even after conserving all possible monsoon flows considerable excess supplies shall be left over, scheme III or I is being proposed for adoption. In Haryana, in the south-west, where groundwaters are saline, scheme II is being proposed.

\section{References}

Bredehoeft J D, Young R A 1970 Water Resources Res. 6: 3-21

Birkoff G, Virga R S, Young D M Jr 1962 Advances in Computers (New York: Academic Press) Vol 3

Chaturvedi M C 1976 Second India Studies-Water (New Delhi: MacMillan)

Duglas J Jr, Rachford H H Jr 1956 Trans. Am. Math. Soc. 82: 421-439

Peaceman D W, Rachford H H Jr $1955 \mathrm{~J}$. Soc. Ind. App. Maths 3: 28-44

Pinder G F, Bredehoeft J D 1968 Water Resources Res. 4: 1069-1093

Pinder G F 1970 An iterative digital model for aquifer evaluation, Open file report US Geol. Survey, $65 \mathrm{pp}$

Prickett T A, Lonnquist C G 1971 Selected digital computer technique for groundwater resource evaluation, Bulletin No. 55, Illinois State Water Survey, Urbana, 62 pp.

Rama 1971 An alternative to Ganga-Cauvery link. Sci. Today, Times of India Publication, Bombay, September

Revelle R, Herman T 1973 Some possibilities for international development of the Ganges-Brahmaputra Basin, First World Congress on Water Resources, International Water Resources Association, Chicago 
Ruben H 1968 Theoretical analysis of two-dimensional transient flow of water in unsaturated and partly unsaturated soils, Proceedings Soil Science of America, 32: 607-615

Saul'yev V K 1964 Integration of the equation of the parabolic type by the method of nets (Oxford; Pergamon Press)

Srivastava V K 1976 Study of induced groundwater recharge, Ph.D. Thesis, Indian Institute of Technology, New Delhi

Thomas Jr H A, Burden R P 1965 Indus river basin studies (mimeo) Division of Engineering and Applied Physics, Harvard University.

Trescott P C 1973 Iterative digital model for aquifer evaluation, Open file report, us Geol. Survey, 63 pp, June.

Young R A, Bredehoeft J D 1972 Water Resources Res., 8: 533-556

Wachpress E L 1965 Iterative solution of elliptic systems (New Jersey: Prentice-Hall)

\section{Appendix A. Finite difference formulation and solution methodology}

The discretization of the basic equation of motion leads to the finite difference equation

$$
\begin{aligned}
& T_{x x}\left|i-\frac{1}{2} j\right|\left|\frac{h_{i-1 j k}-h_{i j k}}{(\Delta x)^{2}}\right|+T_{x x\left|i+\frac{1}{2} j\right|}\left|\frac{h_{i+1 j k}-h_{i j k}}{(\Delta x)^{2}}\right| \\
& \quad+T_{y y\left|j-\frac{1}{2}\right|}\left|\frac{h_{i j-1 k}-h_{i j k}}{(\Delta y)^{2}}\right|+T_{y y|j i+1|}\left|\frac{h_{i j+1 k}-h_{i j k}}{(\Delta y)^{2}}\right| \\
& =S\left|\frac{h_{i j k} h_{i j k-1}}{\Delta t}\right|+\left|\frac{Q_{i j k}}{\Delta x \Delta y}\right|-q_{i j k}^{1}+q_{i j k}^{2}
\end{aligned}
$$

for a rectangular grid, as shown in figure 5 .

The index $k$ represents the $k$ th time step and $i$ and $j$ represent row and column respectively to produce the discretized form. The index $i$ represents the discrete form of $y$ and $j$ represents the discrete form of $x$.

Half-node expansions of transmissivity variable are defined as given by Saulyev (1964).

$$
\begin{aligned}
& T_{\left|i-\frac{1}{2}\right|}=\frac{T_{|i-1 j|}+T_{|i j|}}{2}, \\
& T_{\left|i+\frac{1}{2 j}\right|}=\frac{T_{|i+1 j|}+T_{|i j|}}{2}, \\
& T_{\left|i j-\frac{1}{2}\right|}=\frac{T_{|i j-1|}+T_{|i j|}}{2} \\
& T_{\left|i j+\frac{1}{2}\right|}=\frac{T_{|i j+1|}+T_{|i j|}}{2}
\end{aligned}
$$

The finite difference form of (A.2) and (A.3) become

$$
q_{|i, j|}^{1}=\frac{k_{z|i j|}}{M_{|j j|}}\left[H_{0}-H_{|j i k|}\right]
$$

and

$$
q_{|j| j \mid}^{2}=\frac{k_{E}}{H_{y}}\left[H_{y}-H_{L|j| j \mid}\right]
$$


An ADI procedure is used to solve the equation after substituting the discretized values of the various terms of (A.4). An iterative procedure used by Ruben (1968) is used to increase the accuracy of the method. Application of these techniques to (A.4) leads to two new equations.

$$
\begin{aligned}
& \frac{T_{x x\left|i-\frac{1}{2}\right| j \mid}}{(\Delta x)^{2}} h_{i-1 j k}^{(n+1)}-\left[\frac{T_{x x\left|i-\frac{1}{2} j\right|}}{(\Delta x)^{2}}+\frac{T_{x x\left|i+\frac{1}{2}\right|}}{(\Delta x)^{2}}+\frac{S}{\Delta t}-I_{(i j)}^{(n)}\right] h_{i j k}^{(n+1)}+\frac{T_{x x\left|i+\frac{1}{2}\right|}}{(\Delta x)^{2}} h_{i+1 j k}^{(n+1)} \\
& =\frac{T_{y y\left|i j-\frac{1}{2}\right|}}{(\Delta y)^{2}} h_{i j-1 k-1}^{(n)}+\left[\frac{T_{y y\left|i j-\frac{1}{2}\right|}}{(\Delta y)^{2}}+\frac{T_{y y\left|i j+\frac{1}{2}\right|}}{(\Delta y)^{2}}-\frac{S}{\Delta t} I_{(j i)}^{(n)}\right] h_{i j k-1}^{(n)} \\
& +\frac{T_{y y\left|i j+\frac{1}{1}\right|}}{(\Delta y)^{2}} h_{i j+1 k-1}+\frac{Q_{i j k}}{\Delta x \Delta y}-q_{i j k}^{1}+q_{i j k}^{2}
\end{aligned}
$$

and

$$
\begin{gathered}
\frac{T_{x x\left|j j-\frac{1}{2}\right|}}{(\Delta x)^{2}} h_{i j-1 k}^{(n+1)}-\left[\frac{T_{x x\left|i j-\frac{1}{2}\right|}}{(\Delta x)^{2}}+\frac{T_{x x\left|j j+\frac{1}{2}\right|}}{(\Delta x)^{2}}+\frac{S}{\Delta t}-I_{|i j|}^{(n)}\right] h_{i j k}^{(n+1)} \\
+\frac{T_{x x\left|j i+\frac{1}{1}\right|}}{(\Delta x)^{2}} h_{i j+1 k}^{(n+1)}=\frac{T_{y y\left|i-\frac{1}{j}\right|}}{(\Delta y)^{2}} h_{i-1 j k-1}^{(n)}+\left[\frac{T_{y y|i-1 j|}}{(\Delta y)^{2}}+\frac{T_{y y\left|i+\frac{1}{1}\right|}}{(\Delta y)^{2}}-\frac{S}{\Delta t}-I_{|i j|}^{(n)}\right] h_{i j k-1}^{(n)} \\
+\frac{T_{y y|i+1 j|}}{(\Delta y)^{2}} h_{i+1 j k-1}^{(n)}+\frac{Q_{i j k}}{\Delta x \Delta y}-q_{i j k}^{1}+q_{i j k}^{2}
\end{gathered}
$$

In (A.8) and (A.9) $I_{i j}^{(n)}$ denotes the iteration parameter at the $i$ th and $j$ th node point and is defined by Pinder \& Bredehoeft (1970) as

$$
I_{i j}^{(n)}=I_{i j}^{(10)} \exp \left[l_{n} \frac{2 X_{m}}{\pi} /(\lambda-1)\right]
$$

where $\lambda$ is the number of iteration parameters desired. $X_{m}$ is the larger of the total number of rows and columns in the grid and

$$
I^{(i)}=\frac{\pi^{2}}{2 X_{m}^{2}} \frac{1}{1+\frac{(\Delta x)^{2}}{(\Delta y)^{2}}}\left[T_{\left|i-\frac{1}{2} j\right|}+T_{\left|i+\frac{1}{2} j\right|}+T_{\left|i j-\frac{1}{2}\right|}+T_{\left|i j+\frac{1}{2}\right|}\right],
$$

where $\Delta x$ is maximum grid spacing and $\Delta y$ is minimum grid spacing given by Trescott (1973).

Known values are on the right side of (A.8) and (A.9). For the imposed grid, (A.8) and (A.9) form two systems of linear equations. The first set represents the row values with column values held fixed and the second set represents the column values with row values held fixed. The values of $h_{i j k-1}^{(n)}$ and $h_{i j k}^{(n+1)}$ are compared for all $i$ 's and $j$ 's. If the absolute value of their difference is less than some convergence factor $\varepsilon$ the timeincrement counter $k$ is advanced to $k+1$; if not, the iterative parameter index $n$ is advanced and $k$ remains fixed, until convergence is achieved. The time duration $\Delta t$ may be large with iterative procedure. The program has two options on the time either to simulate a given number of time steps or to simulate a given pumping period.

The transmissivity is computed at each iteration as product of saturated thickness and hydraulic conductivity at each node. The program is set up to terminate 
computations when a pumping well "goes dry". For nodes that go dry other than pumping nodes a saturated thickness of $0.305 \mathrm{~m}$ (on an empirical basis) is maintained so that a saturated layer is maintained at the top and the unsaturated region is not introduced. The program also has the facility of multiple pumping periods.

The program is set up to terminate computations to save computer time when the solution approaches steady state long before the end of the pumping period. Withdrawal from a well node is assumed to occur over the area of influence of the well node. Drawdown at a pumping node, therefore, is considerably less than would be observed in a real well. The real well drawdown can be predicted by plotting drawdown versus the log of distance for nodes near the pumping node (excluding those directions in which other wells are within two nodes) and extrapolating to the radius of a real well. Alternatively, these data can be used in the Theim equation to calculate the additional drawdown in a fully penetrating real well.

Two major assumptions are made in treating the leakage from the multiple pumping periods. Dimensionless time for the previous pumping period is assumed to be so large that storage in the confining bed has a negligible effect on the leakage from this period. For a real problem involving pumping periods of months to years in length this is a reasonable assumption. Rainfall infiltration recharge is treated as pumping into the aquifer. A check is provided that the water table does not rise above the top of the aquifer during computation. If very high recharge rate from rainfall is assumed the program will not allow the water-table to rise above the top of the aquifer in such cases. The water level in the source, from which leakage takes place, can be changed over various pumping periods to simulate the real situations over long pumping periods and the effect of leakage is included implicitly.

The grid spacing in the two directions can be different and quite large. However, smaller grid spacing and shorter time periods will give better results. 